05

\title{
Теплопроводность и термоэдс соединений системы $\mathrm{Cu}-\mathrm{Ge}-\mathrm{As}-\mathrm{Se}$
}

\author{
() О.П. Щетников, Н.В. Мельникова, А.Н. Бабушкин, В.М. Кисеев \\ Уральский федеральный университет им. первого Президента России Б.Н. Ельцина, \\ Институт естественных наук и математики, \\ 620002 Екатеринбург, Россия \\ e-mail: o.shchetnikov@yandex.ru
}

Поступило в Редакцию 1 мая 2020 г.

В окончательной редакции 11 июля 2020 г.

Принято к публикации 16 июля 2020 г.

Проанализировано влияние температур $(300-400 \mathrm{~K})$ и концентраций на электропроводность, термоэдс и коэффициент теплопроводности кристаллических материалов на основе халькогенидов меди с общей формулой $(\mathrm{GeSe})_{1-x}\left(\mathrm{CuAsSe}_{2}\right)_{x}$. Определены механизмы переноса тепла. Выявлена немонотонность температурной зависимости теплопроводности с аномалией при $358 \mathrm{~K}$. Вычислена термоэлектрическая добротность $Z T$.

Ключевые слова: термоэдс, коэффициент Зеебека, теплопроводность, электропроводность, термоэлектрическая добротность, термоэлектрические преобразователи, полупроводники, халькогениды меди.

DOI: 10.21883/JTF.2021.01.50271.156-20

\section{Введение}

Халькогенидные системы с гомологическими рядами слоистых соединений, в частности тройные и четверные халькогениды со сложными кристаллическими решетками и низкой решеточной теплопроводностью, могут представлять интерес с точки зрения применения в качестве эффективных термоэлектрических материалов, а также в связи со сложным электронно-ионным переносом, оказывающим влияние на теплофизические характеристики.

Селенид германия имеет достаточно высокий коэффициент Зеебека $\left(\sim 600 \mu \mathrm{V} \cdot \mathrm{K}^{-1}\right)$ и относится к группе материалов, перспективных для использования в термоэлектрических преобразователях (например, $[1,2])$. $\mathrm{CuAsSe}{ }_{2}$ имеет структуру сфалерита и представляет собой соединение с плотно упакованными слоями селена. Медь и мышьяк размещаются в тетраэдрических пустотах в чередующихся прослойках [3].

Ранее исследованные особенности поведения электрофизических характеристик системы $\mathrm{Cu}-\mathrm{Ge}-\mathrm{As}-\mathrm{Se}[3-5]$ в широком интервале температур и давлений показали, что электросопротивление уменьшается с ростом давления, и в материалах наблюдается отрицательное магнитосопротивление.
Целью наших исследований является изучение концентрационных и температурных зависимостей теплопроводности и термоэдс четверных халькогенидов $(\mathrm{GeSe})_{1-x}(\mathrm{CuAsSe})_{x}$, имеющих достаточно высокий коэффициент Зеебека, а также выявление перспективности их использования в термоэлектрических преобразователях.

\section{1. Синтез образцов}

Синтез соединений осуществляли путем сплавления реактивов высокой чистоты в кварцевых ампулах, вакуумированных до остаточного давления $10^{-4} \mathrm{~Pa}$ и заполненных обескислороженным инертным газом до $0.5 \cdot 10^{5}$ Ра с последующим ступенчатым плавным повышением температуры до $1370 \mathrm{~K}$, выдержкой и плавным охлаждением до комнатной температуры [6]. Структура образцов приведена в таблице (для смеси фаз - весовые проценты).

\section{2. Методика измерений}

Измерения электропроводности проводили четырехзондовым методом на постоянном токе. Измерения температурных зависимостей термоэдс проводили с приме-

Кристаллическая структура исследованных образцов $(\mathrm{GeSe})_{1-x}\left(\mathrm{CuAsSe}_{2}\right)_{x}$ [7]

\begin{tabular}{|c|c|c|c|c|c|c|c|c|c|}
\hline$x$ & $\begin{array}{c}0 \\
(\mathrm{GeSe})\end{array}$ & 0.1 & 0.2 & 0.3 & 0.4 & 0.6 & 0.7 & 0.8 & $\begin{array}{c}1 \\
\left(\mathrm{CuAsSe}_{2}\right)\end{array}$ \\
\hline Сингония & Орторомб & Смесь фаз & Орторомб & Куб & Тетрагон & Тетрагон & Тетрагон & Орторомб & Куб \\
\hline Параметры & $\begin{array}{l}a=1.083 \\
b=0.383 \\
c=0.439\end{array}$ & $\begin{array}{c}\text { GeSe } 63 \% \\
\mathrm{Cu}_{2} \mathrm{GeSe}_{3} 31 \% \\
\mathrm{CuAsSe}_{2} 6 \%\end{array}$ & $\begin{array}{l}a=1.085 \\
b=0.384 \\
c=0.438\end{array}$ & $a=0.554$ & $\begin{array}{l}a=0.395 \\
c=0.549\end{array}$ & $\begin{array}{l}a=0.395 \\
c=0.548\end{array}$ & $\begin{array}{l}a=0.394 \\
c=0.547\end{array}$ & $\begin{array}{l}a=0.549 \\
b=0.550 \\
c=0.558\end{array}$ & $a=0.549$ \\
\hline
\end{tabular}


нением комплекса приборов Modulelab Solartron System, в состав которого входит многофункциональная ячейка Probostat. Испытуемый образец помещали между двумя платиновыми электродами в замкнутой алундовой измерительной ячейке. В образцах поддерживали градиент температуры от 4 до $5 \mathrm{~K}$.

Теплопроводность измеряли на модифицированном измерителе ИТ- $\lambda-400$, использующем метод динамического калориметра. Слитки синтезированных халькогенидов по размеру меньше, чем стандартный образец, поэтому изготавливали композитную вставку, в центральной части которой располагался вырезанный из слитка имеющий форму прямоугольного параллелепипеда образец, залитый эпоксидной смолой с известной теплопроводностью. Тогда при условии параллельного включения тепловых потоков через исследуемый халькогенид и эпоксидную смолу теплопроводности образца и смолы будут давать аддитивные вклады в суммарную теплопроводность композита, и коэффициент теплопроводности изучаемого материала можно рассчитать, используя соотношение

$$
\lambda_{\text {samp }}=\frac{\lambda_{\text {gen }} S_{g e n}-\lambda_{\text {epox }} S_{\text {epox }}}{S_{\text {samp }}}
$$

где $\lambda_{\text {samp }}-$ теплопроводность халькогенида, $\lambda_{\text {gen }}-$ теплопроводность композитной вставки, $S_{g e n}$ - площадь сечения вставки, $\lambda_{\text {epox }}-$ теплопроводность эпоксидной смолы, $S_{\text {epox }}$ - площадь сечения эпоксидной смолы, $S_{\text {samp }}$ - площадь сечения халькогенида. Погрешность измерения абсолютного значения теплопроводности не превышает $10 \%$, относительного $-1 \%$.

Добротность термоэлектрических материалов оценивалась путем вычисления безразмерного коэффициента $Z T$

$$
Z T=\frac{\alpha^{2} \sigma T}{\lambda_{\text {samp }}},
$$

где $T-$ абсолютная температура, $\alpha-$ коэффициент термоэдс материала, $\sigma$ - его удельная электропроводность.

\section{3. Результаты и обсуждение}

\section{1. Температурные зависимости теплопроводности}

При измерениях теплопроводности обнаружено, что для составов всех концентраций температурные зависимости теплопроводности не подчиняются закону $\lambda_{\text {samp }} \propto T^{-1}$ (рис. 1), т.е. для данной системы материалов фононная теплопроводность не является основным механизмом переноса тепла.

При этом теплопроводность при комнатной температуре для образцов $x=0.1$ максимальна (около $\left.5 \mathrm{~W} \cdot \mathrm{m}^{-1} \cdot \mathrm{K}^{-1}\right)$ для исследованной системы. Учитывая, что по структурным данным (см. таблицу) этой концентрации соответствует смесь фаз с преобладанием

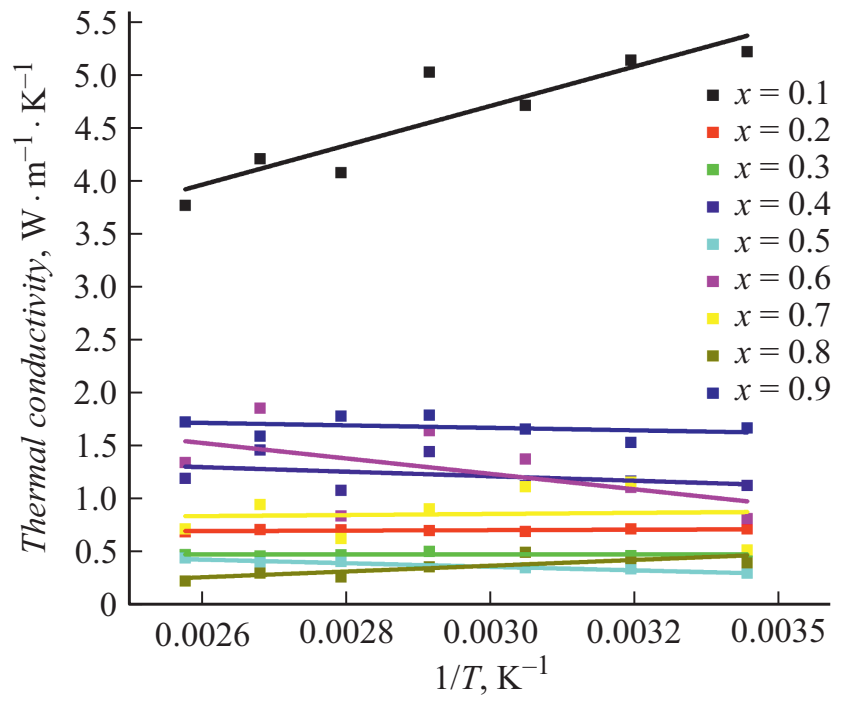

Рис. 1. Зависимости теплопроводности $(\mathrm{GeSe})_{1-x}\left(\mathrm{CuAsSe}_{2}\right)_{x}$ от обратной температуры.

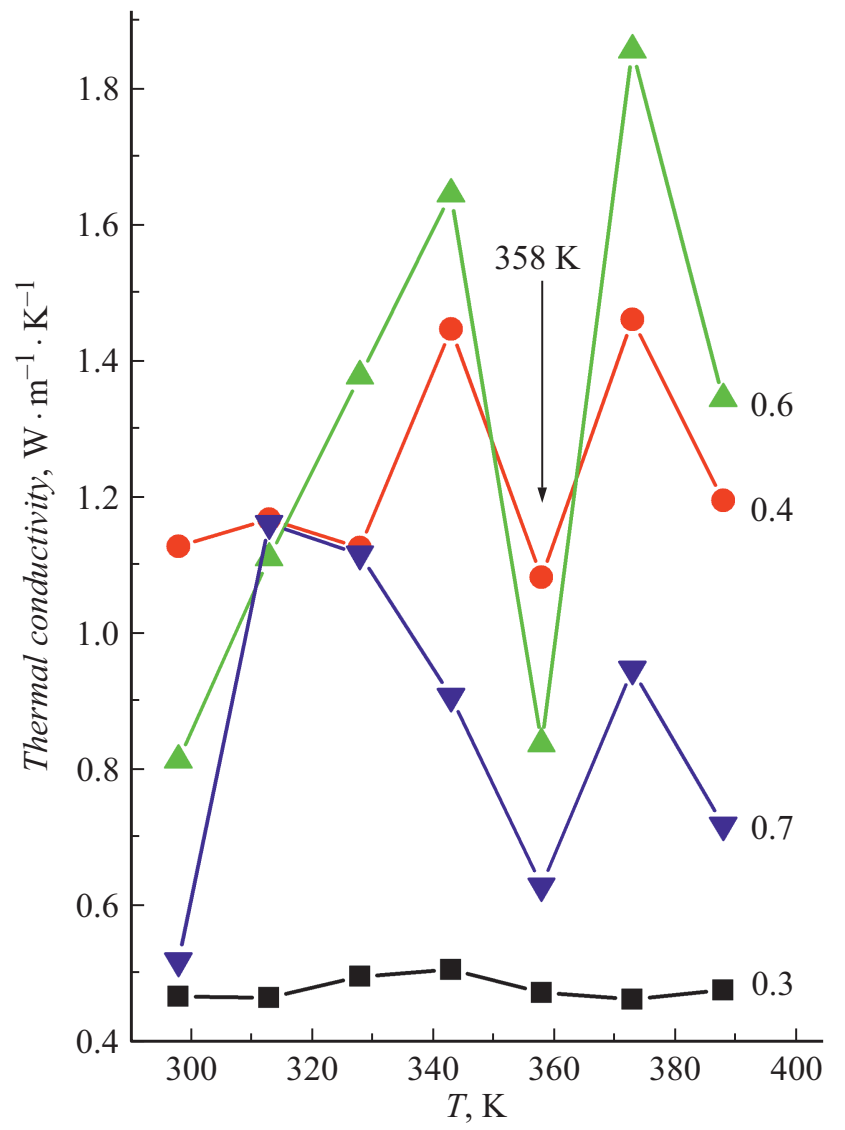

Рис. 2. Температурные зависимости теплопроводности $(\mathrm{GeSe})_{1-x}\left(\mathrm{CuAsSe}_{2}\right)_{x}$. Значения $x$ приведены на рисунке.

селенида германия, можно ожидать что именно это соединение дает основной вклад в теплопроводность. Заметим, что теплопроводность селенида германия при комнатной температуре около $2 \mathrm{~W} \cdot \mathrm{m}^{-1} \cdot \mathrm{K}^{-1}$ и определяется фононным механизмом рассеяния [8]. 
При изменении концентрации $\mathrm{CuAsSe} 2$ ситуация изменяется. При концентрациях $x=0.4,0.6$ и 0.7 теплопроводность от температуры зависит немонотонно и имеет минимум при $358 \mathrm{~K}$ (рис. 2). Это позволяет предположить, что в тетрагональной фазе (см. таблицу) происходит изменение механизма переноса тепла, и существенный вклад в теплопроводность вносят нефонные механизмы рассеяния.

\section{2. Концентрационные зависимости электропроводности}

Селенид германия является полупроводником с дырочным типом проводимости, шириной запрещенной зоны $0.87 \mathrm{eV}$. Электропроводность поликристаллического GeSe, синтезированного аналогичным описанному методом, при комнатной температуре составляет около $0.49 \mathrm{~S} \cdot \mathrm{m}^{-1}[1]$. Однофазное соединение $\mathrm{CuAsSe}_{2}$ в
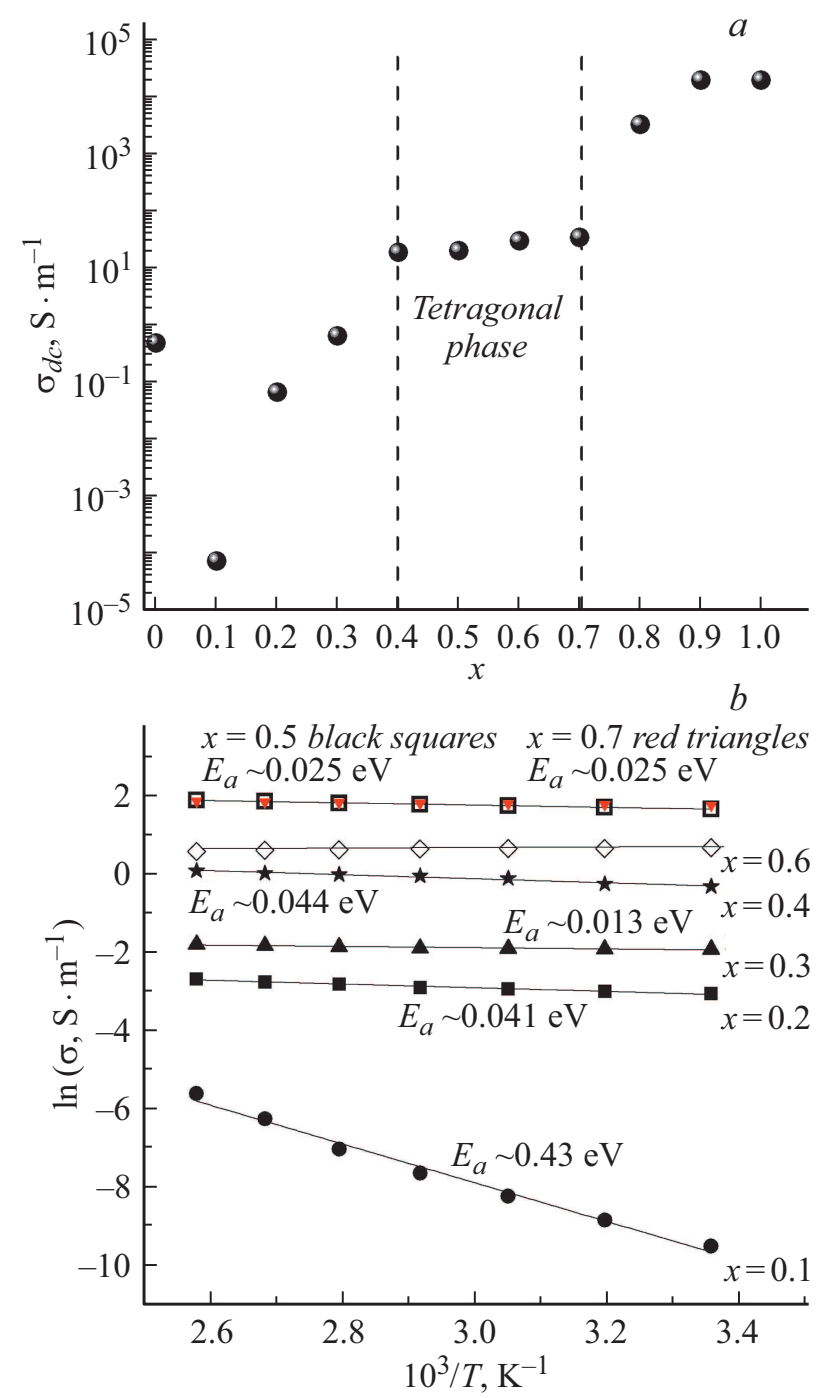

Рис. 3. Зависимость электропроводности на постоянном токе от состава при комнатной температуре $(a)$ и температурные зависимости электропроводности $(b)$ материалов $(\mathrm{GeSe})_{1-x}\left(\mathrm{CuAsSe}_{2}\right)_{x}$.

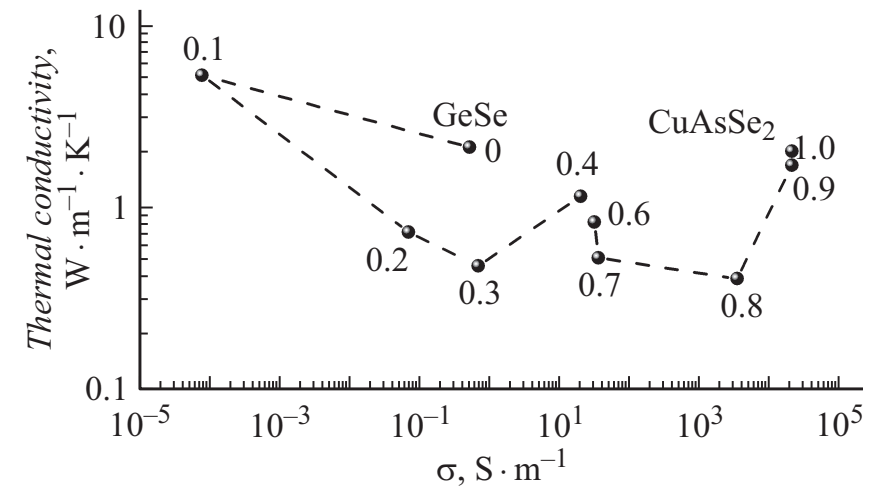

Рис. 4. Связь между электропроводностью и теплопроводностью образцов системы $(\mathrm{GeSe})_{1-x}\left(\mathrm{CuAsSe}_{2}\right)_{x}$. Значения $x$ приведены на рисунке.

твердом состоянии - примесный полупроводник с металлическим характером проводимости [9]. По данным ряда исследований, обобщенных в [10], $\mathrm{CuAsSe} 2$ имеет проводимость около $2 \cdot 10^{4} \mathrm{~S} \cdot \mathrm{m}^{-1}$.

На рис. 3 приведены концентрационные зависимости проводимости изученных материалов. Абсолютная величина проводимости $(\mathrm{GeSe})_{1-x}\left(\mathrm{CuAsSe}_{2}\right)_{x}$ достаточно велика и существенно зависит от состава. Из рисунка видно, что в кубической и орторомбической фазах с $x$ меньше 0.3 проводимость не превышает $0.6 \mathrm{~S} \cdot \mathrm{m}^{-1}$, при переходе в тетрагональную фазу проводимость резко возрастает от $19 \mathrm{~S} \cdot \mathrm{m}^{-1}$ для $x=0.4$ до $34 \mathrm{~S} \cdot \mathrm{m}^{-1}$ при $x=0.7$. При $x=0.8$ проводимость резко увеличивается почти на два порядка до $\sim 3000 \mathrm{~S} \cdot \mathrm{m}^{-1}$. Для всех составов при значениях $x$ от 0.1 до 0.7 электропроводность имеет активационную природу, для составов $x=0.8$, 0.9 практически не зависит от температуры, что свидетельствует о высокой концентрации носителей заряда и подтверждает известные данные [10].

Для составов с $x=0.8,0.9$ слабая зависимость теплопроводности от температуры может свидетельствовать о вкладе электронной составляющей теплопроводности. Однако оценки в соответствии с [11] показали, что электронный вклад в теплопроводность не превышает 1\%. На рис. 4 приведена диаграмма, иллюстрирующая связь теплопроводности и электропроводности образцов изученной системы.

\section{3. Температурные и концентрационные зависимости термоэдс и термоэлектрической добротности}

На рис. 5 приведены температурные зависимости термоэдс материалов, относящихся к тетрагональной фазе. Для других фаз термоэдс как минимум на один порядок величины меньше. Знак коэффициента Зеебека указывает на дырочную проводимость всех изученных соединений. 


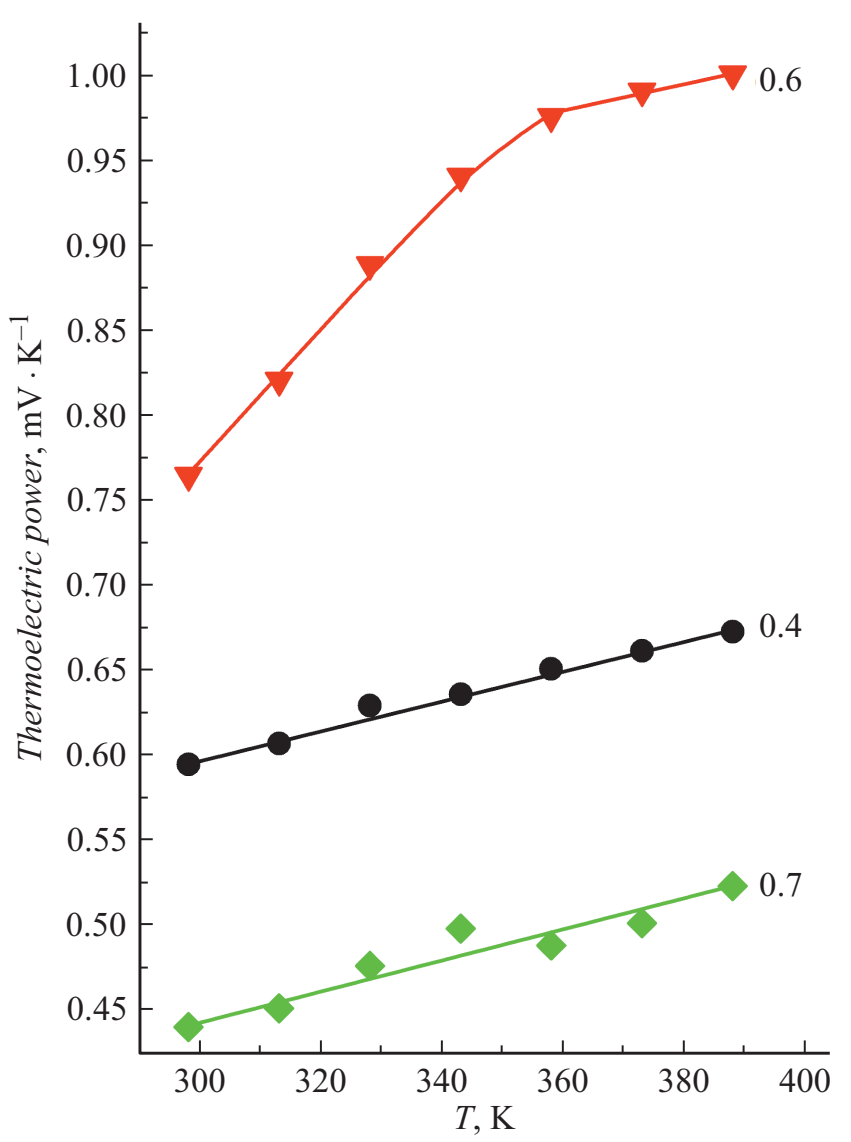

Рис. 5. Температурные зависимости термоэдс $(\mathrm{GeSe})_{1-x}\left(\mathrm{CuAsSe}_{2}\right) x$, имеющих тетрагональную структуру. Значения х приведены на рисунке.

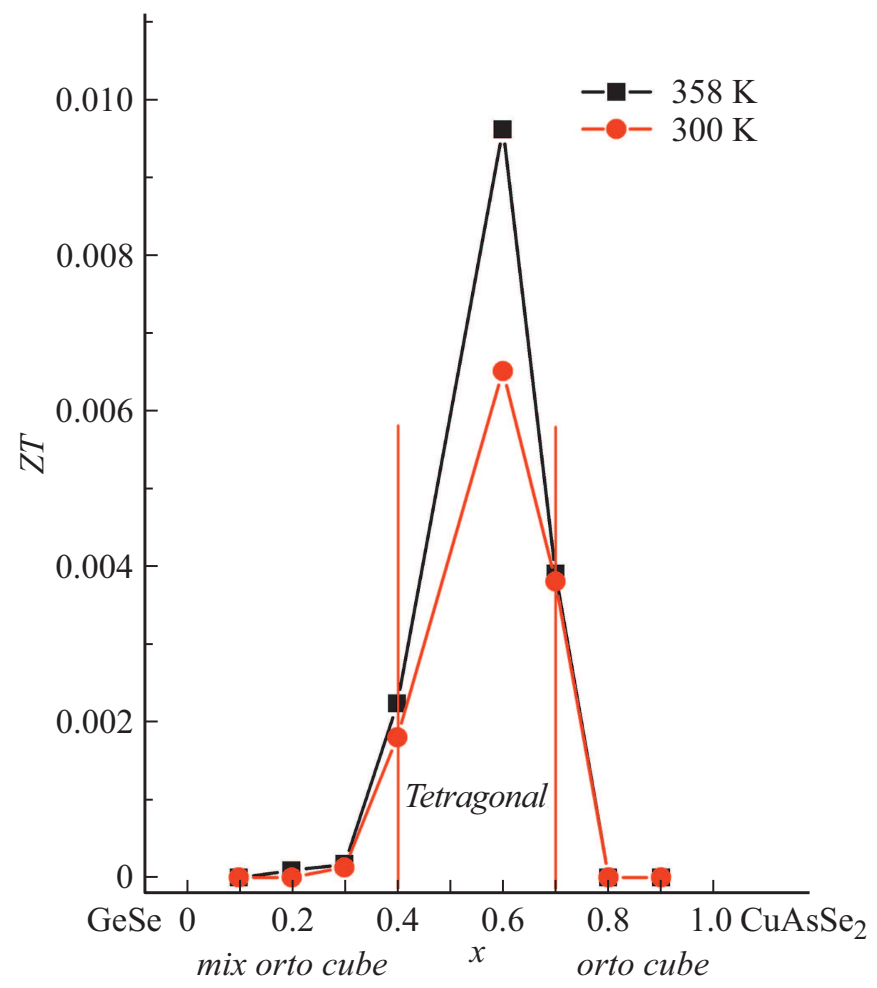

Рис. 6. Концентрационные зависимости термоэлектрической добротности $(\mathrm{GeSe})_{1-x}\left(\mathrm{CuAsSe}_{2}\right)_{x}$ при 300 и $358 \mathrm{~K}$.
Из этих зависимостей видно, что термоэдс в исследованном диапазоне $T=300-400 \mathrm{~K}$ монотонно возрастает с температурой, причем максимальное значение коэффициента Зеебека (около $1000 \mu \mathrm{V} \cdot \mathrm{K}^{-1}$ ) имеется у системы с $x=0.6$.

На рис. 6 показана концентрационная зависимость термоэлектрической добротности исследованных материалов при 300 и $358 \mathrm{~K}$, температуре, при которой теплопроводность тетрагональной фазы имеет минимальное значение.

Видно, что максимальная термоэлектрическая добротность материалов системы $(\mathrm{GeSe})_{1-x}\left(\mathrm{CuAsSe}_{2}\right)_{x}$ наблюдается для $x=0.6$ в тетрагональной кристаллической структуре. Особенности поведения всех изученных характеристик при $x=0.6$ до конца не понятны. Резкий рост добротности в узком интервале концентраций позволяет предложить способ заметного повышения термоэлектрической добротности - снижение теплопроводности за счет создания дополнительных барьеров для переноса тепла при уменьшении размеров зерен и при легировании наноматериалами, например нанотрубками.

\section{Заключение}

При проведении исследований теплопроводности, термоэдс и электропроводности материалов системы $(\mathrm{GeSe})_{1-x}\left(\mathrm{CuAsSe}_{2}\right)_{x}$ показано, что электропроводность монотонно изменяется при изменении температуры и концентрации, термоэдс монотонно изменяется при изменении температуры, причем значение коэффициента Зеебека достаточно велико. Обнаружено, что теплопроводность ведет себя сложным образом. Для всех концентраций теплопроводность не может быть объяснена наличием процессов переброса, что указывает на присутствие доминирующего механизма, не характерного для рассеяния энергии на колебаниях кристаллической решетки. В то же время электронный вклад в теплопроводность составляет не более $1 \%$. Для тетрагональной фазы теплопроводность меняется с температурой немонотонно и имеет особенность при $358 \mathrm{~K}$. Именно в этой фазе резко возрастает термоэлектрическая добротность $Z T$, имеющая максимальное значение 0.01 при $358 \mathrm{~K}$.

\section{Конфликт интересов}

Авторы заявляют, что у них нет конфликта интересов.

\section{Список литературы}

[1] О.А. Игнатченко, А.Н. Бабушкин, Н.В. Мельникова. ФТТ, 35 (8), 1983 (1993).

[2] M. Sist, C. Gatti, P. Norby, S. Cenedese, H. Kasai, K. Kato, B.B. Iversen. Chemistry, 23 (28), 6888 (2017). DOI: $10.1002 /$ chem. 201700536

[3] R.M. Imamov, I.I. Petrov. Sov. Phys. Crystallogr., 13, 335 (1968). 
[4] V.E. Zaikova, N.V. Melnikova, A.V. Tebenkov, A.A. Mirzorakhimov, O.P. Shchetnikov, A.N. Babushkin, G.V. Sukhanova. J. Phys. Conf. Ser., 917 (8), 082009 (2017).

DOI: $10.1088 / 1742-6596 / 917 / 8 / 082009$

[5] Н.В. Мельникова, А.Н. Бабушкин, О.В. Савина. ФТВД, 19 (1), 63 (2009).

[6] Н.В. Мельникова, Л.А. Сайпулаева, П.П. Хохлачев, А.Ю. Моллаев, А.Г. Алибеков, К.В. Курочка, О.Л. Хейфец, А.Н. Бабушкин. ФТТ, 57 (10), 1972 (2015). [N.V. Melnikova, L.A. Saipulaeva, P.P. Khokhlachev, A.Y. Mollaev, A.G. Alibekov, K.V. Kurochka, O.L. Kheifets, A.N. Babushkin. Phys. Solid State, 57 (10), 2025 (2015).

DOI: $10.1134 / \mathrm{S} 1063783415100200]$

[7] Н.В. Мельникова, Л.Я. Кобелев, В.Б. Злоказов. Письма в ЖТФ, 21 (1), 9 (1995). [N.V. Mel'Nikova, L.Ya. Kobelev, V.B. Zlokazov. Tech. Phys. Lett., 21 (1), 3 (1995).]

[8] A.S. Okhotin, A.N. Krestovnikov, A.A. Aivazov, A.S. Pushkarskii. Phys. Stat. Sol. (b), 31, 485 (1969).

DOI: $10.1002 /$ pssb.19690310206

[9] Г.Г. Гаджиев, Я.Б. Магомедов, Ш.М. Исмаилов. ТВТ, 8 (1), 213 (1970). [G.G. Gadzhiev, Ya.B. Magomedov, Sh.M. Ismailov. High Temp., 8 (1), 204 (1970).]

[10] J.L. Shay, J.H. Wernick. Ternary Chalcopyrite Semiconductors: Growth, Electronic Properties, and Applications (Pergamon press 1td, Headington Hill Hall, Oxford. 2017) v. 7.

[11] B. Dzundza, L. Nykyruy, T. Parashchuk, E. Ivakin, Y. Yavorsky, L. Chernyak, Z. Dashevsky. Physica B: Physics of Condensed Matter, 588, 412178 (2020).

DOI: https://doi.org/10.1016/j.physb.2020.412178 